\title{
UM ESTUDO SOBRE A EVOLUÇÃO DAS TERMINOLOGIAS DA EXPRESSÃO "PESSOAS COM DEFICIÊNCIA": A PROPOSIÇÃO DE UMA NOVA NOMENCLATURA COMO CONCRETIZAÇÃO DA DIGNIDADE HUMANA CONTEMPORÂNEA
}

\section{Álvaro dos Santos Maciel*}

\section{RESUMO}

No Brasil há poucas evidências que se debruçam quanto à discussão terminológica acerca da expressão "pessoa com deficiência". Com objetivo de incitar debates, pretende-se exteriorizar uma reflexão de natureza epistemológica no intuito de construir uma nova nomenclatura, porém humanizada. Para tanto, foi utilizada pesquisa bibliográfica e levantamento de documentos com fulcro no método hipotético dedutivo. Conclui-se que é possível a adoção de nova expressão que acabe com os paradoxos terminológicos presentes em ideias como eficiência e deficiência, e que sejam criados termos que denotem uma identidade "não negativa" do grupo em questão.

Palavras-chave: Pessoas com deficiência; evolução terminológica; capacitismo; pessoa com diversidade funcional; epistemologia.

\section{A STUDY ON THE EVOLUTION OF THE TERMINOLOGIES OF THE EXPRESSION "DISABLED PEOPLE": THE PROPOSITION OF A NEW NOMENCLATURE AS A RESULT OF CONTEMPORARY HUMAN DIGNITY}

\begin{abstract}
In Brazil there is little evidence that deals with the terminological discussion about the expression "disable people". In order to incite debates, it is intended to express an epistemological reflection in order to build a new nomenclature, however humanized. For this purpose, a bibliographic search and document survey with fulcrum was used in the hypothetical deductive method. The conclusion reveals that it is possible to adopt a new expression that does away with the terminological paradoxes present in ideas such as efficiency and disability, and that terms are created that denote a "non-negative" identity of the group in question.
\end{abstract}

Keywords: Disable people; terminological evolution; capacitism; person with functional diversity; epistemology.

\section{INTRODUÇÃO}

\footnotetext{
* Doutor em Ciências Jurídicas e Sociais pela Universidade Federal Fluminense (UFF, 2017) com estágio sanduíche na Universidade de Lisboa (UL, 2016), Mestre em Ciências Jurídicas pela Universidade Estadual do Norte do Paraná (UENP, 2010), com especialização em Direito Civil e Processual Civil pela Universidade Estadual de Londrina (UEL, 2007). Graduado em Direito pela Universidade Norte do Paraná (2004). Bolsista pela CAPES (2013-2017), Pesquisador visitante pela Universidade de Lisboa (2016). Advogado e Professor de Graduação e Pós-Graduação, com experiência em cargos de gestão, núcleos laboratoriais e prática jurídica.
} 
Várias pesquisas demonstram as práticas discriminatórias que, ao longo da história, as pessoas com deficiência (PcD’s) foram subjugadas (SILVA, 1987; ALBRECHT; SEELMAN; BURY, 2001; GUGEL, 2008), o que pode ser evidenciado inclusive por estudos realizados quanto ao uso das imagens e terminologias empregadas para caracterizar este grupo nas artes (SHAKESPEARE, 1999; SILVEIRA, 2012) e em mídias sociais de diversos países tais como Portugal (PINTO, 2014), Canadá (DEVOTTA; WILTON; YIANNAKOULIAS, 2013), Estados Unidos (HARNETT, 2000; HALLER; DORRIES; RAHN, 2006), Reino Unido (HUNT, 1991; EMMA; WATSON; PHILO, 2011), Austrália (GOGGIN, 2009; JONES, 2009), Ucrânia (PHILLIPS, 2012) e Brasil (CARLI, 2003; VIVARTA, 2003; ANSELMO, 2017; DIAS; PETRUSKI, 2017). Todos são uníssonos ao tangenciar a ideia de que, de certa forma, o que vemos, ouvimos e lemos geralmente é decidido e influenciado por um pequeno grupo de tomadores de decisão, tais quais os editores, produtores, programadores e investidores que muitas vezes são influenciados por suas próprias opiniões de deficiência, e assim retratam as pessoas como objetos de curiosidade ou violência, castigo divino, fardos, seres assexuados, incapazes de participar da vida diária, heroica, super humana, dentre outras classificações.

Os empregos dos termos e dos discursos se fazem do ponto de vista da realidade em que a terminologia é utilizada e então reflete um dado momento histórico correspondente em que, nem sempre o termo, que hoje nos revela preconceito, possuía, na época, tal conotação (SASSAKI, 2002, 2003; GARCIA, 2010).

No Brasil há poucas evidências que se debruçam quanto à discussão terminológica que aqui se propõe (HARLOS \& DENARI, 2012). Com objetivo de incitar debates e de refletir sobre as questões assinaladas, pretende-se exteriorizar uma reflexão de natureza epistemológica, com um enfoque específico na questão da nomenclatura. Para tanto, foi utilizada pesquisa bibliográfica e levantamento de documentos com fulcro no método hipotético dedutivo.

A problemática da pesquisa reside no fato de que a terminologia deflagra preconceitos diversos e pode ser a causa de exclusão social haja vista que a pessoa é estigmatizada com o rótulo de déficit apenas por apresentar determinada diversidade. Dessa maneira, que expressões são perpetuadas através dos tempos? Quais os significados “concretos” que a elas se associam? Têm sido sugeridas novas expressões? 


\section{UM ESTUDO SOBRE A EVOLUÇÃO DAS TERMINOLOGIAS DA EXPRESSÃO “PESSOAS COM \\ DEFICIÊNCIA": A PROPOSIÇÃO DE UMA NOVA NOMENCLATURA COMO CONCRETIZAÇÃO DA \\ DIGNIDADE HUMANA CONTEMPORÂNEA}

Justifica-se o presente estudo porque a linguagem é capaz de produzir, modificar e direcionar o pensamento e as práticas sociais e, dialeticamente, também é modificada, produzida e orientada por mudanças de conceitos sociais.

\section{As terminologias numa perspectiva evolucionária}

Diante do atual momento da história, no intuito de repensar inclusive o termo pessoa com deficiência, hoje utilizado pela legislação internacional e nacional, revela-se interessante demonstrar como ocorreu a evolução das nomenclaturas no Brasil e o que elas significavam em termos da imagem que a sociedade tinha acerca das PcD's. Para tanto, fundamentando-se inicialmente nos vários estudos elaborados por Sassaki (2003), passa-se a reproduzir, com algumas adaptações, os quadros apresentados pelo mesmo.

Quadro 1. Nomenclatura: inválidos (Fonte: Sassaki, 2003, adaptado)

\begin{tabular}{|c|c|c|}
\hline ÉPOCA & $\begin{array}{c}\text { TERMOS E } \\
\text { SIGNIFICADOS }\end{array}$ & VALOR DA PESSOA \\
\hline Meados do séc. $X X$ & $\operatorname{Inv}$ & \multirow[b]{2}{*}{$\begin{array}{l}\text { Aquele que tinha } \\
\text { deficiência era tido como } \\
\text { socialmente inútil, um peso } \\
\text { morto para a sociedade, um } \\
\text { fardo para a família, } \\
\text { alguém sem valor } \\
\text { profissional. } \\
\text { Outros exemplos: } \\
\text { "Servidor inválido pode } \\
\text { voltar" (Folha de S. Paulo, } \\
\text { 20/7/82). } \\
\text { "Os cegos e o inválido" } \\
\text { (Isto É, 7/7/99). }\end{array}$} \\
\hline $\begin{array}{l}\text { Romances, nomes de } \\
\text { instituições, leis, mídia e } \\
\text { outros meios mencionavam } \\
\text { “os inválidos". Exemplos: } \\
\text { "A reabilitação profissional } \\
\text { visa a proporcionar aos } \\
\text { beneficiários inválidos ..." } \\
\text { (Decreto federal no } 60.501 \text {, } \\
\text { de } 14 / 3 / 67 \text {, dando nova } \\
\text { redação ao Decreto no } \\
\text { 48.959-A, de 19/9/60). }\end{array}$ & $\begin{array}{c}\text { O termo significava } \\
\text { "indivíduos sem valor". } \\
\text { Em pleno século 20, ainda } \\
\text { se utilizava este termo, } \\
\text { embora sem nenhum } \\
\text { sentido pejorativo na } \\
\text { época. } \\
\text { Outro exemplo: } \\
\text { "Inválidos insatisfeitos } \\
\text { com lei relativa aos } \\
\text { ambulantes" } \\
\text { (Diário Popular, 21/4/76). }\end{array}$ & \\
\hline
\end{tabular}

Como Sassaki (2003) destaca, via de regra, a sociedade naturalmente enxergava as PcD's como indivíduos "sem valor" ou "incapazes" para o trabalho ou para a vida social, o que gerava a exclusão. 
Outra expressão apresentada pelo Quadro a seguir revela o avanço social de um período que outrora excluía para um período de integração social, ocasião em que houve progressivo crescimento de instituições que visavam ao atendimento especializado para as PcD’s.

Quadro 2. Nomenclatura: incapacitados (Fonte: Sassaki, 2003, adaptado)

\begin{tabular}{|c|c|c|}
\hline ÉPOCA & $\begin{array}{c}\text { TERMOS E } \\
\text { SIGNIFICADOS }\end{array}$ & VALOR DA PESSOA \\
\hline $\begin{array}{c}\text { Entre aproximadamente } \\
1920 \text { e } 1960\end{array}$ & Incapacitados & \\
\hline $\begin{array}{c}\text { “Privativo para } \\
\text { incapacitados" (Shopping } \\
\text { News, Coluna } \\
\text { Radioamadorismo, 1973). } \\
\text { “Escolas para crianças } \\
\text { incapazes" (Shopping } \\
\text { News, 13/12/64). } \\
\text { Após a I e a II Guerras } \\
\text { Mundiais: "A guerra } \\
\text { produziu incapacitados", } \\
\text { "Os incapacitados agora } \\
\text { exigem reabilitação física". } \\
\text { Art. 5 do Código Civil } \\
\text { (BRASIL, 1916) }\end{array}$ & $\begin{array}{l}\text { O termo significava, de } \\
\text { início, “indivíduos sem } \\
\text { capacidade” e, mais tarde, } \\
\text { evoluiu e passou a } \\
\text { significar "indivíduos com } \\
\text { capacidade residual”. } \\
\text { Durante várias décadas, era } \\
\text { comum o uso deste termo } \\
\text { para designar pessoas com } \\
\text { deficiência de qualquer } \\
\text { idade. Uma variação foi o } \\
\text { termo “os incapazes", que } \\
\text { significava “indivíduos que } \\
\text { não são capazes” de fazer } \\
\text { algumas coisas por causa } \\
\text { da deficiência que tinham. }\end{array}$ & $\begin{array}{l}\text { Foi um avanço a sociedade } \\
\text { reconhecer que a pessoa } \\
\text { com deficiência poderia ter } \\
\text { capacidade residual, } \\
\text { mesmo que reduzida. Mas, } \\
\text { ao mesmo tempo, } \\
\text { considerava-se que a } \\
\text { deficiência, qualquer que } \\
\text { fosse o tipo, eliminava ou } \\
\text { reduzia a capacidade da } \\
\text { pessoa em todos os } \\
\text { aspectos: físico, } \\
\text { psicológico, social, } \\
\text { profissional etc. }\end{array}$ \\
\hline
\end{tabular}

Atribuir incapacidade aos efeitos da deficiência é resultado do julgamento e do olhar gaze (PINTO, 2012) que o modelo médico empreendia em suas concepções sobre a temática, o que interferiu fortemente na construção de conceitos e expressões em todas as outras áreas. A crítica consistia nos debates propostos por outros modelos de abordagem que desassociam a incapacidade como consequência imediata da deficiência.

\footnotetext{
${ }^{2}$ Art. 5. do antigo Código Civil Brasileiro com vigência entre 1916 e 2002: "São absolutamente incapazes de exercer pessoalmente os atos da vida civil: (...) II - os loucos de todo o gênero; III - os surdos-mudos, que não puderem exprimir a sua vontade; (...)." (g.n)
} 


\section{UM ESTUDO SOBRE A EVOLUÇÃO DAS TERMINOLOGIAS DA EXPRESSÃO “PESSOAS COM \\ DEFICIÊNCIA": A PROPOSIÇÃO DE UMA NOVA NOMENCLATURA COMO CONCRETIZAÇÃO DA \\ DIGNIDADE HUMANA CONTEMPORÂNEA}

Quadro 3. Nomenclatura: defeituosos, deficientes e excepcionais

(Fonte: Sassaki, 2003, adaptado)

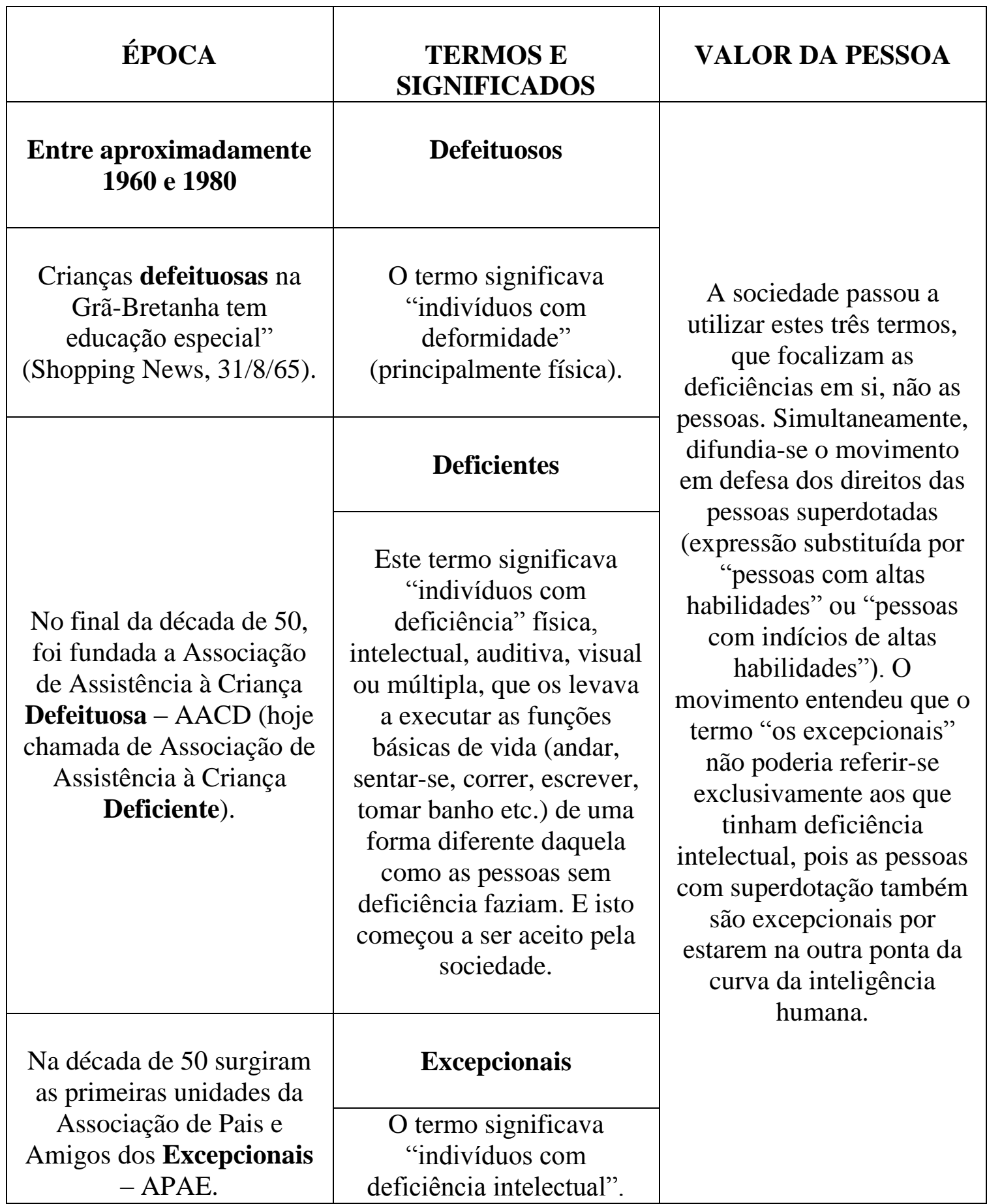

A crítica contemporânea a estes termos consiste na ausência da palavra "pessoa" pelo fato do indivíduo estar sendo classificado por dotar uma característica "anormal", "diferente". 
Destaca-se que o termo "defeituoso" carreia ainda uma ideia de objetificação do ser humano. O modelo de abordagem médica, por se relacionar ao paradigma da integração dessas pessoas, associou-se à utilização de tais termos por classificar a "anormalidade" da PcD.

Quadro 4. Nomenclatura: pessoas deficientes (Fonte: Sassaki, 2003, adaptado)

\begin{tabular}{|c|c|c|}
\hline ÉPOCA & $\begin{array}{c}\text { TERMOS E } \\
\text { SIGNIFICADOS }\end{array}$ & VALOR DA PESSOA \\
\hline $\begin{array}{l}\text { Entre aproximadamente } \\
1981 \text { e } 1987\end{array}$ & Pessoas deficientes & $\begin{array}{l}\text { A Organização Mundial de } \\
\text { Saúde (OMS) lançou em } \\
1980 \text { a CIDID, e mostrou }\end{array}$ \\
\hline $\begin{array}{c}\text { Por pressão das } \\
\text { organizações de pessoas } \\
\text { com deficiência, a ONU } \\
\text { deu o nome ao ano de } \\
1981 \text { de "Ano } \\
\text { Internacional das Pessoas } \\
\text { Deficientes". }\end{array}$ & $\begin{array}{c}\text { Pela primeira vez o } \\
\text { substantivo "deficientes" } \\
\text { (como em "os deficientes") } \\
\text { passou a ser utilizado como } \\
\text { adjetivo, sendo-lhe } \\
\text { acrescentado o substantivo } \\
\text { "pessoas". }\end{array}$ & $\begin{array}{l}\text { (impedimentos, deficiências } \\
\text { e incapacidades) podem } \\
\text { existir simultaneamente em } \\
\text { cada pessoa com } \\
\text { deficiência. } \\
\text { Foi atribuído o valor } \\
\text { "pessoas" àqueles que } \\
\text { tinham deficiência, } \\
\text { igualando-os em direitos e } \\
\text { dignidade à maioria dos } \\
\text { membros de qualquer } \\
\text { sociedade. }\end{array}$ \\
\hline
\end{tabular}

Estabeleceu-se, por conseguinte que, antes do atributo deficiência, o ser humano se faz presente. Essa mudança, que pode parecer sutil e talvez até implicar a ideia de "tanto faz" demonstra avanço no poder do discurso e nos anseios dos movimentos das PcD’s que pleiteavam por mais respeito pois até então as nomenclaturas as consideravam uma "espécie à parte" do grupo social.

Quadro 5. Nomenclatura: portadores de deficiência (Fonte: Sassaki, 2003, adaptado)

\begin{tabular}{|c|c|c|}
\hline ÉPOCA & $\begin{array}{c}\text { TERMOS E } \\
\text { SIGNIFICADOS }\end{array}$ & VALOR DA PESSOA \\
\hline $\begin{array}{c}\text { Entre aproximadamente } \\
1988 \text { e } 1993\end{array}$ & $\begin{array}{c}\text { Pessoas portadoras de } \\
\text { deficiência }\end{array}$ & $\begin{array}{c}\text { O "portar uma deficiência" } \\
\text { passou a ser um valor, um } \\
\text { detalhe agregado à pessoa. }\end{array}$ \\
\hline
\end{tabular}




\section{UM ESTUDO SOBRE A EVOLUÇÃO DAS TERMINOLOGIAS DA EXPRESSÃO “PESSOAS COM \\ DEFICIÊNCIA": A PROPOSIÇÃO DE UMA NOVA NOMENCLATURA COMO CONCRETIZAÇÃO DA \\ DIGNIDADE HUMANA CONTEMPORÂNEA}

\begin{tabular}{|c|c|c|}
\hline $\begin{array}{c}\text { Alguns líderes de } \\
\text { organizações de pessoas } \\
\text { com deficiência } \\
\text { contestaram o termo } \\
\text { "pessoa deficiente" } \\
\text { alegando que transmite a } \\
\text { ideia de que a pessoa } \\
\text { inteira seria deficiente. } \\
\text { Constituição Federal } \\
\text { (BRASIL, 1988). Art. } 23 \text {. } \\
\text { É competência comum da } \\
\text { União, dos Estados, do } \\
\text { Distrito Federal e dos } \\
\text { Municípios: II - cuidar da } \\
\text { saúde e assistência pública, } \\
\text { da proteção e garantia das } \\
\text { pessoas portadoras de } \\
\text { deficiência. }\end{array}$ & $\begin{array}{l}\text { Termo foi proposto para } \\
\text { substituir o termo “pessoas } \\
\text { deficientes". Expressão } \\
\text { utilizada somente em } \\
\text { países de língua } \\
\text { portuguesa. }\end{array}$ & $\begin{array}{l}\text { O termo foi adotado na } \\
\text { Constituição Federal e em } \\
\text { todas as leis e políticas } \\
\text { pertinentes ao campo das } \\
\text { deficiências. Conselhos, } \\
\text { coordenadorias e } \\
\text { associações passaram a } \\
\text { incluir o termo em seus } \\
\text { nomes oficiais. }\end{array}$ \\
\hline $\begin{array}{c}\text { Constituição Federal } \\
\text { (BRASIL, 1988). Art. } 208 . \\
\text { O dever do Estado com a } \\
\text { educação será efetivado } \\
\text { mediante a garantia de: III } \\
\text { - atendimento educacional } \\
\text { especializado aos } \\
\text { portadores de deficiência, } \\
\text { preferencialmente na rede } \\
\text { regular de ensino. }\end{array}$ & $\begin{array}{l}\text { Pela lei do menor esforço, } \\
\text { o termo foi reduzido para } \\
\text { "portadores de } \\
\text { deficiência". }\end{array}$ & \\
\hline
\end{tabular}

Em que pese a contestação dos movimentos se baseava na ideia de que por serem "pessoas" mereciam ser valorizadas como tal, e por isso destacavam o fato de que não eram "inteiramente deficientes" houve a crítica da nomenclatura "pessoas deficientes" que vinha sendo utilizada, e este foi o cerne dos debates que antecederam a Constituição de 1988 para a substituição do referido termo. Porém, mesmo que a Lei Maior, quando de sua publicação, tenha adotado na maior parte das vezes a expressão "pessoas portadoras de deficiência", por vezes subtraiu a expressão "pessoa" como se denota no artigo 208 ainda original em que elenca tão somente o uso do termo "portadores de deficiência", assim também ocorreu com várias leis posteriores. 
O termo "portador de deficiência" passou a ser criticado já que, com o tempo levou-se a ideia de que a deficiência podia ser algo retirado e colocado em qualquer momento, como por exemplo, o uso de óculos.

Quadro 6. Nomenclatura: pessoas com necessidades especiais (Fonte: Sassaki, 2003, adaptado)

\begin{tabular}{|c|c|c|}
\hline ÉPOCA & $\begin{array}{c}\text { TERMOS E } \\
\text { SIGNIFICADOS }\end{array}$ & VALOR DA PESSOA \\
\hline De 1990 até hoje & $\begin{array}{c}\text { Pessoas com necessidades } \\
\text { especiais }\end{array}$ & \multirow[b]{2}{*}{$\begin{array}{l}\text { De início, "necessidades } \\
\text { especiais" representava } \\
\text { apenas um novo termo. } \\
\text { Depois, com a vigência da } \\
\text { Resolução n.2, } \\
\text { "necessidades especiais" } \\
\text { passou a ser um valor } \\
\text { agregado tanto à pessoa } \\
\text { com deficiência quanto a } \\
\text { outras pessoas, detendo um } \\
\text { significado próprio. }\end{array}$} \\
\hline $\begin{array}{c}\text { O art. } 5 \text { da resolução } \\
\text { CNE/CEB n }{ }^{\circ} 2 \text {, de } 11 / 9 / 01, \\
\text { explica que as } \\
\text { necessidades especiais } \\
\text { decorrem de três situações, } \\
\text { uma das quais envolvendo } \\
\text { dificuldades vinculadas a } \\
\text { deficiências e dificuldades } \\
\text { não-vinculadas a uma } \\
\text { causa orgânica. }\end{array}$ & $\begin{array}{c}\text { O termo surgiu para } \\
\text { substituir "deficiência" por } \\
\text { "necessidades especiais". } \\
\text { Daí a expressão "pessoas } \\
\text { com necessidades } \\
\text { especiais". }\end{array}$ & \\
\hline $\begin{array}{l}\text { Surgiram expressões como } \\
\text { "pessoas especiais", }\end{array}$ & Pessoas especiais & $\begin{array}{l}\text { O termo "especiais" } \\
\text { permanece como uma }\end{array}$ \\
\hline
\end{tabular}

\footnotetext{
${ }^{3} \mathrm{O}$ inteiro teor do Art. $5^{\circ}$ da referida resolução do Conselho Nacional de Educação, ao instituir diretrizes nacionais para a educação especial na educação básica, assim esclarece: "Consideram-se educandos com necessidades educacionais especiais os que, durante o processo educacional, apresentarem: I - dificuldades acentuadas de aprendizagem ou limitações no processo de desenvolvimento que dificultem o acompanhamento das atividades curriculares, compreendidas em dois grupos: a) aquelas não vinculadas a uma causa orgânica específica; b) aquelas relacionadas a condições, disfunções, limitações ou deficiências; II - dificuldades de comunicação e sinalização diferenciadas dos demais alunos, demandando a utilização de linguagens e códigos aplicáveis; III altas habilidades/superdotação, grande facilidade de aprendizagem que os leve a dominar rapidamente conceitos, procedimentos e atitudes."
} 


\begin{tabular}{|c|c|c|}
\hline $\begin{array}{c}\text { "crianças especiais", } \\
\text { "alunos especiais", } \\
\text { "pacientes especiais" numa } \\
\text { tentativa de amenizar a } \\
\text { contundência da palavra } \\
\text { "deficientes". }\end{array}$ & $\begin{array}{c}\text { simples palavra, sem } \\
\text { agregar valor diferenciado } \\
\text { às pessoas com deficiência. } \\
\text { O "especial" não é } \\
\text { predicativo exclusivo das } \\
\text { o termo foi reduzido para } \\
\text { "pessoas especiais" } \\
\text { pessoas com deficiência, já } \\
\text { que se aplica a qualquer } \\
\text { pessoa. }\end{array}$ \\
\hline
\end{tabular}

O propósito da resolução em destaque do Ministério da Educação (MEC), ao utilizar o termo "necessidades especiais" era identificar pessoas que apresentassem necessidades educacionais especiais, ou seja, diferentes do grupo de alunos com comportamento médio ou padrão. Dessa forma, não se tratava especificamente de pessoas com deficiência, porém, o uso do termo passou a ser veiculado de modo geral em diferentes áreas numa tentativa de humanizar a expressão "deficiência” tida como pejorativa.

Observa-se que as PcD’s têm experiências e narrativas pessoais que até podem causar sentimentos de "doença", “dor" e "medo" (WENDELL, 1996), porém apresentam sentimentos, virtudes e defeitos, qualidades positivas ou negativas, como qualquer outro indivíduo. Resta um flagrante equívoco estereotipá-las como especiais no intuito de transmitir a ideia de "seres dependentes, moralmente carentes, ou heroicos, assexuados, e/ou miseráveis".. Dito de outro modo, a deficiência não pode ser o balizador que qualifica e determina a especialidade, a capacidade e o caráter das pessoas.

Quadro 7. Nomenclatura: pessoas com deficiência - terminologia atual (Fonte: Sassaki, 2003, adaptado)

\begin{tabular}{|c|c|c|}
\hline ÉPOCA & $\begin{array}{c}\text { TERMOS E } \\
\text { SIGNIFICADOS }\end{array}$ & VALOR DA PESSOA \\
\hline De 1990 até hoje & Pessoas com Deficiência & $\begin{array}{c}\text { Os valores agregados às } \\
\text { pessoas com deficiência } \\
\text { são: }\end{array}$ \\
\hline
\end{tabular}




\begin{tabular}{|c|c|c|}
\hline $\begin{array}{l}\text { A década de } 90 \text { e a } \\
\text { primeira década do século } \\
21 \text { e do Terceiro Milênio } \\
\text { são marcadas por eventos } \\
\text { mundiais, liderados por } \\
\text { organizações de pessoas } \\
\text { com deficiência. }\end{array}$ & $\begin{array}{l}\text { Termo preferido por um } \\
\text { número cada vez maior de } \\
\text { adeptos pelo mundo. No } \\
\text { Brasil, o maior evento } \\
\text { ("Encontrão") das } \\
\text { organizações do grupo, } \\
\text { realizado no Recife/PE em } \\
\text { 2000, clamaram ao público } \\
\text { a adotar este termo, ao } \\
\text { esclarecer que que não são } \\
\text { "portadoras de deficiência" } \\
\text { e que não querem ser } \\
\text { chamadas com tal nome. }\end{array}$ & $\begin{array}{l}\text { 1) o do empoderamento } \\
\text { (uso do poder pessoal para } \\
\text { fazer escolhas, tomar } \\
\text { decisões e assumir o } \\
\text { controle da situação de } \\
\text { cada um); } \\
\text { 2) o da responsabilidade de } \\
\text { contribuir com seus } \\
\text { talentos para mudar a } \\
\text { sociedade rumo à inclusão } \\
\text { de todas as pessoas, com } \\
\text { ou sem deficiência. }\end{array}$ \\
\hline
\end{tabular}

A terminologia pessoas com deficiência é o mais recente termo adotado formalmente pela legislação internacional, como por exemplo, na Convenção sobre os Direitos da Pessoa com Deficiência (CDPD) aprovada pela ONU em 2006 e, ratificada pelo Brasil em 2008 (BRASIL, 2008).

Assim, ratifica-se o expresso na Parte I do presente Capítulo, que esta pesquisa opta por respeitar o profundo e variado debate internacional dos estudos sobre deficiência (disability studies) e seguir os ditames propostos pela CDPD, e, portanto, adota o emprego da expressão pessoas com deficiência ao referir-se às pessoas que, por questões variadas apresentam diversidade funcional e experimentam a deficiência.

As justificativas para o uso "correto" do termo são apresentadas por Sassaki (2003) que arrola os seguintes motivos:

Quadro 8. Justificativas para o uso da terminologia correta (Fonte: Sassaki, 2003, adaptado)

1. Não esconder ou camuflar a deficiência;

2. Não aceitar o consolo da falsa ideia de que todo mundo tem deficiência;

3. Mostrar com dignidade a realidade da deficiência;

4. Valorizar as diferenças e necessidades decorrentes da deficiência;

5. Combater neologismos que tentam diluir as diferenças, tais como "pessoas com capacidades especiais", "pessoas com eficiências diferentes", "pessoas com habilidades diferenciadas", "pessoas deficientes", "pessoas especiais", "é desnecessário discutir a questão das deficiências porque todos nós somos imperfeitos".

6. Defender a igualdade entre as pessoas com deficiência e as demais pessoas em 


\section{UM ESTUDO SOBRE A EVOLUÇÃO DAS TERMINOLOGIAS DA EXPRESSÃO “PESSOAS COM DEFICIÊNCIA": A PROPOSIÇÃO DE UMA NOVA NOMENCLATURA COMO CONCRETIZAÇÃO DA \\ DIGNIDADE HUMANA CONTEMPORÂNEA}

termos de direitos e dignidade, o que exige a equiparação de oportunidades para pessoas com deficiência atendendo às diferenças individuais e necessidades especiais, que não devem ser ignoradas;

7. Identificar nas diferenças todos os direitos que lhes são pertinentes e a partir daí encontrar medidas específicas para o Estado e a sociedade diminuírem ou eliminarem as "restrições de participação" (dificuldades ou incapacidades causadas pelos ambientes humanos e físicos contra as pessoas com deficiência).

Embora sejam um conceito e uma nomenclatura em constante progresso, como bem reconhecido pela CDPD ao expressar em seu Preâmbulo [...] reconhecendo que a deficiência é um conceito em evolução [...] e em seu artigo $1^{\circ}$ tê-las conceituado como aquelas (pessoas) que têm impedimentos de longo prazo de natureza física, mental, intelectual ou sensorial, os quais, em interação com diversas barreiras, podem obstruir sua participação plena e efetiva na sociedade em igualdade de condições com as demais pessoas, há uma inquietação que esta pesquisa se debruça e que traz a lume acerca da necessidade política, jurídica, sociológica, médica, cultural de ter que classificar as pessoas, afinal o questionamento que se faz está em descobrir o momento em será possível construir e designar uma construção neutra da deficiência com aduz Silvers (2013), mesmo considerando as narrativas pessoais e todas as consequências e experiências que disso pode resultar, porém sem agregar qualquer tipo de estigmatização. Ou seja, em que pese a necessidade de discriminação positiva enquanto política pública, será possível as pessoas com deficiência serem enxergadas como pessoas antes de serem enxergadas em seus limites? Será possível uma nomenclatura que não esconda a deficiência, mas que enfoque muito mais a pessoa em sua totalidade para só depois enxergar a diversidade? Será possível construir um "ponto morto" acerca da deficiência que seja livre de presunções apaixonadas, politizadas ou estigmatizadas?

Oliver (1990), critica a nomenclatura "pessoa com deficiência" porque acredita que a deficiência não é um detalhe do indivíduo, e sim, uma base social indispensável que compõe a identidade dos indivíduos, logo, não faz sentido falar sobre pessoas e deficiência separadamente, e sim "deficientes” ou "pessoas deficientes” já que a demanda é por aceitação como são.

De qualquer forma, o adjetivo utilizado não pode se sobrepor à pessoa, sob pena de, a partir daí, compor-se uma visão estereotipada das PcD. Pastore (2001) define a questão da repulsa social inerente a qualificações pejorativas: 
É isso que acontece quando as pessoas se referem ao paralítico, ao cego, ao surdoetc. Elas destacam, em primeiro lugar, o atributo - e não o ser humano. Com base nisso, passam a imputar ao portador daquela limitação um conjunto de imperfeições que ele não tem. É assim que se forma o estigma. Quem tem estigma é tratado, pelos preconceituosos, como um ser não inteiramente humano. $\mathrm{O}$ estigma se agrava quando, por exemplo, se juntam numa só pessoa o fato de ser deficiente, mulher e negra. Neste caso, fala-se em 'opressão simultânea'. É a sociedade que transforma muitas pessoas eficientes em deficientes.

Parece uma lacuna de difícil compreensão, porém é evidente, que a democracia, ao adotar na prática isônomica o discurso de que "somos todos iguais na diferença", o sentido de vagas preferenciais, de recursos educacionais especiais ou da "Lei de Cotas" (BRASIL, 1991) para vagas de emprego continua a ser legítimo e persistir, pois a neutralidade está em conceber inclusive, novas propostas de nomenclatura para as PcD's sem deixar de apostar na isonomia em todos os aspectos possíveis, e sem, por óbvio, descaracterizar as narrativas e experiências de natureza física, sensorial ou cognitiva que a diversidade funcional pode deflagrar.

\section{UMA ANÁLISE CRÍTICA DO USO DA EXPRESSÃO: LEVANTAMENTO DOCUMENTAL}

Trata-se de uma implementação contemporânea a nomenclatura pessoas com deficiência aos indivíduos que "têm impedimentos de longo prazo de natureza física, mental, intelectual ou sensorial, os quais, em interação com diversas barreiras, podem obstruir sua participação plena e efetiva na sociedade em igualdade de condições com as demais pessoas" (CDPD, 2006), e tratá-las coletivamente, independente do tipo e do grau de limitação numa concepção neutra, de igual modo é também um fenômeno recente (SILVERS, 2003) ${ }^{4}$, eis que historicamente, a denominação eram realizadas de acordo com as alterações físicas ou mentais das pessoas. Elas eram descritas como aleijadas, surdas, cegas, loucas, débeis, etc. (SILVA, 1987; ALBRECHT; SEELMAN; BURY, 2001; GUGEL, 2008).

A título de exemplo acerca da evolução dos termos e da confusão terminológica, fez-se uma pesquisa entre os 2 maiores jornais de grande circulação digital no Brasil, "Folha de São de Paulo" e "O Globo", plataformas virtuais o uso das expressões constantes aleatoriamente nas páginas digitalizadas.

\footnotetext{
${ }^{4}$ Em seus estudos, Anita Silvers, filósofa americana, elabora teorias acerca da necessidade de repensar a deficiência como um todo e sugere que, para que haja a neutralidade do conceito em si e o despojo da negatividade que nela está instrínseca, deve haver uma remodelagem tanto por parte da visão médica quanto pela comunidade em geral.

${ }^{5}$ São 34 os jornais que tiveram circulação digital no Brasil na variação dos anos 2014-2015 de acordo com a Associação Nacional de Jornais <http://www.anj.org.br/maiores-jornais-do-brasil/>, acesso em 15/07/2016. Foram
} 


\section{UM ESTUDO SOBRE A EVOLUÇÃO DAS TERMINOLOGIAS DA EXPRESSÃO “PESSOAS COM DEFICIÊNCIA": A PROPOSIÇÃO DE UMA NOVA NOMENCLATURA COMO CONCRETIZAÇÃO DA \\ DIGNIDADE HUMANA CONTEMPORÂNEA}

A Folha de São de Paulo $^{6}$ permite consulta virtual em todos os seus cadernos digitalizados desde o ano de 1921, porém apresenta resultados a partir de 1950. Para objetivar a pesquisa, procurou-se detalhar o aparecimento das expressões, por décadas. O critério de seleção das expressões buscadas foi aleatório, porém considerando os verbetes referenciados nos Quadros anteriores.

Quadro 9. Nomenclaturas na história da deficiência na Folha de São Paulo (1951-2016)

\begin{tabular}{|c|c|c|c|c|c|c|c|}
\hline \multicolumn{8}{|c|}{ FOLHA DE SÃO PAULO } \\
\hline Expressões buscadas & $\begin{array}{r}1951- \\
1960\end{array}$ & $\begin{array}{r}1961- \\
1970\end{array}$ & $\begin{array}{r}1971- \\
1980\end{array}$ & $\begin{array}{r}1981- \\
1990\end{array}$ & $\begin{array}{r}1991- \\
2000\end{array}$ & $\begin{array}{r}2001- \\
2010\end{array}$ & $\begin{array}{r}2011- \\
2016\end{array}$ \\
\hline $\begin{array}{l}\text { pessoas com necessidades } \\
\text { especiais, pessoa com } \\
\text { necessidade especial }\end{array}$ & 0 & 0 & 0 & 0 & 1 & 29 & 124 \\
\hline $\begin{array}{l}\text { portadores de necessidades } \\
\text { especiais, portador de } \\
\text { necessidades especiais }\end{array}$ & 0 & 0 & 0 & 0 & 27 & 48 & 0 \\
\hline $\begin{array}{l}\text { crianças especiais, criança } \\
\text { especial }\end{array}$ & 0 & 0 & 6 & 18 & 47 & 37 & 19 \\
\hline pessoas deficientes & 0 & 1 & 19 & 251 & 25 & 14 & 8 \\
\hline $\begin{array}{l}\text { portadores de deficiência, } \\
\text { portador de deficiência, portador } \\
\text { de deficiências }\end{array}$ & 0 & 1 & 21 & 81 & 416 & 409 & 1 \\
\hline pessoa inválida & 0 & 3 & 8 & 3 & 0 & 1 & 0 \\
\hline pessoas excepcionais & 0 & 3 & 10 & 4 & 5 & 3 & 2 \\
\hline $\begin{array}{l}\text { pessoas com deficiência, pessoas } \\
\text { com deficiências, pessoa com } \\
\text { deficiência }\end{array}$ & 0 & 14 & 17 & 44 & 251 & 522 & 1867 \\
\hline paralítico & 2 & 54 & 160 & 411 & 223 & 69 & 25 \\
\hline incapacitado & 4 & 58 & 95 & 125 & 80 & 77 & 42 \\
\hline aleijado & 5 & 60 & 138 & 102 & 64 & 51 & 21 \\
\hline $\begin{array}{l}\text { retardados mentais, retardado } \\
\text { mental, retardo mental, retardos } \\
\text { mentais }\end{array}$ & 6 & 50 & 121 & 93 & 130 & 109 & 45 \\
\hline deformidades, deformidade & 10 & 119 & 119 & 159 & 206 & 168 & 66 \\
\hline deformados, deformado & 15 & 138 & 276 & 505 & 271 & 203 & 87 \\
\hline
\end{tabular}

escolhidos apenas os 2 primeiros como destaque desta pesquisa tendo em vista a facilidade de acesso eletrônico às informações necessárias.

${ }^{6}$ Disponível de forma pública pelo endereço eletrônico <http://acervo.folha.uol.com.br/busca_detalhada/>, acesso em 15/07/2016. O site de buscas da Folha de São Paulo diferencia expressões plural e singular demandando a digitação de verbetes exatos. Permite a busca desde 1921, porém apresenta resultados a partir do ano de $1950 \mathrm{em}$ todos os cadernos. Não foi identificado se necessariamente o verbete faz referência à pessoa. 


\begin{tabular}{|c|c|c|c|c|c|c|c|}
\hline $\begin{array}{l}\text { pessoas incapacitadas, pessoa } \\
\text { incapacitada, criança } \\
\text { incapacitada, crianças } \\
\text { incapacitadas, pessoa incapaz, } \\
\text { criança incapaz, pessoas } \\
\text { incapazes, crianças incapazes }\end{array}$ & 20 & 14 & 37 & 34 & 32 & 31 & 19 \\
\hline defeituosos, defeituoso & 22 & 159 & 387 & 350 & 357 & 236 & 117 \\
\hline retardados, retardado & 45 & 389 & 707 & 705 & 414 & 272 & 104 \\
\hline inválidos, inválido, desvalido & 50 & 444 & 558 & 394 & 349 & 294 & 120 \\
\hline deficientes, deficiente & 117 & 1141 & 3255 & 4451 & 9136 & 7600 & 3847 \\
\hline
\end{tabular}

Uma avaliação da Folha de São de Paulo demonstra a evolução ao longo das décadas da expressão ora em debate. Não obstante a nomenclatura atual seja "pessoas com deficiência", a expressão mais incidente desde a década de 50 é "deficientes(s)". Ao considerar que a CDPD é de 2006 e sua influência internacional, observa-se o crescimento do uso desta expressão nas últimas décadas, porém, ainda atrás da desatualizada expressão “deficiente(s)".

Vê-se nas décadas de 50 e 60 um alto uso das expressões como "inválido(s) e desvalido" seguido por "retardado(s)", dentre outras. Na década de 70 a expressão "retardado(s)" ganha mais incidência que "inválido(s) e desvalido", seguida de outras; na década de 80, nomenclaturas como "pessoas deficientes", "paralíticos", “deformados" ganham latência, não obstante ainda ficam atrás das incidências como "retardado(s)", "defeituoso(s)" e "deficientes"; a década de 90 é o ápice do uso das expressões "deficientes" e "portadores de deficiência". Finalmente, do ano dois mil em diante há mais incidência de expressões como "deficientes", "pessoas com deficiência", "portadores de deficiência" e "pessoas com necessidades especiais". De qualquer modo, expressões como "inválido" e "defeituoso" podem ser usadas como sinônimas para qualificar outras questões que não as pessoas, e este estudo não se debruçou no saber de qual uso estavam a ser empregadas tais palavras haja vista que o enfoque principal é demonstrar apenas um panorama genérico do uso do discurso. Portanto, se subtraídos tais verbetes do quadro em nada trará prejuízo já que outras expressões permanecem revelando a evolução dos termos. 


\section{UM ESTUDO SOBRE A EVOLUÇÃO DAS TERMINOLOGIAS DA EXPRESSÃO “PESSOAS COM DEFICIÊNCIA": A PROPOSIÇÃO DE UMA NOVA NOMENCLATURA COMO CONCRETIZAÇÃO DA \\ DIGNIDADE HUMANA CONTEMPORÂNEA}

O Jornal "O Globo"7 permite consulta virtual em todos os seus cadernos digitalizados desde o ano de 1921, momento em que disponibiliza os resultados. De igual modo ao jornal a anterior, para objetivar a pesquisa, procurou-se detalhar por décadas.

Quadro 10. Nomenclaturas na história da deficiência no Jornal O Globo (1921-2016)

\begin{tabular}{|c|c|c|c|c|c|c|c|c|c|c|}
\hline \multicolumn{11}{|c|}{ O GLOBO } \\
\hline Expressões buscadas & $\begin{array}{r}1921 \\
- \\
1930 \\
\end{array}$ & $\begin{array}{r}1931 \\
- \\
1940 \\
\end{array}$ & $\begin{array}{r}1941 \\
- \\
1950\end{array}$ & $\begin{array}{r}1951 \\
- \\
1960\end{array}$ & $\begin{array}{r}1961 \\
- \\
1970 \\
\end{array}$ & $\begin{array}{r}1971 \\
- \\
1980\end{array}$ & $\begin{array}{r}1981 \\
- \\
1990\end{array}$ & $\begin{array}{r}1991 \\
- \\
2000 \\
\end{array}$ & $\begin{array}{r}2001 \\
- \\
2010\end{array}$ & $\begin{array}{r}2010 \\
- \\
2016 \\
\end{array}$ \\
\hline $\begin{array}{l}\text { pessoa com } \\
\text { necessidade especial }\end{array}$ & 0 & 0 & 0 & 0 & 0 & 0 & 0 & 2 & 22 & 92 \\
\hline $\begin{array}{l}\text { portador de } \\
\text { necessidades especiais }\end{array}$ & 0 & 0 & 0 & 0 & 0 & 0 & 3 & 87 & 165 & 247 \\
\hline pessoas deficientes & 0 & 0 & 0 & 2 & 4 & 12 & 352 & 67 & 23 & 19 \\
\hline $\begin{array}{l}\text { pessoas com } \\
\text { deficiência }\end{array}$ & 0 & 0 & 0 & 3 & 6 & 30 & 46 & 101 & 320 & 649 \\
\hline portador de deficiência & 0 & 0 & 0 & 6 & 49 & 64 & 313 & 1377 & 1125 & 518 \\
\hline pessoas excepcionais & 0 & 0 & 2 & 6 & 8 & 21 & 24 & 32 & 12 & 15 \\
\hline criança especial & 0 & 1 & 30 & 22 & 36 & 38 & 168 & 671 & 151 & 133 \\
\hline pessoa inválida & 0 & 3 & 7 & 12 & 11 & 16 & 9 & 13 & 3 & 0 \\
\hline $\begin{array}{l}\text { retardado mental, } \\
\text { retardo mental }\end{array}$ & 1 & 5 & 4 & 67 & 148 & 159 & 106 & 207 & 53 & 31 \\
\hline paralítico & 3 & 11 & 316 & 749 & 716 & 1028 & 1099 & 1215 & 346 & 103 \\
\hline $\begin{array}{l}\text { pessoas incapacitadas, } \\
\text { criança incapacitada, } \\
\text { pessoa incapaz, } \\
\text { criança incapaz }\end{array}$ & 4 & 9 & 2 & 27 & 49 & 55 & 48 & 41 & 25 & 21 \\
\hline incapacitado & 19 & 72 & 197 & 338 & 576 & 512 & 352 & 372 & 194 & 100 \\
\hline deformidade & 71 & 27 & 41 & 115 & 184 & 261 & 303 & 460 & 217 & 196 \\
\hline deformado & 90 & 215 & 281 & 519 & 840 & 1005 & 878 & 814 & 447 & 215 \\
\hline aleijado & 97 & 244 & 189 & 306 & 268 & 381 & 278 & 250 & 247 & 72 \\
\hline deficientes & 222 & 1058 & 1258 & 1388 & 2196 & 3854 & 6814 & 8311 & 7918 & 3011 \\
\hline defeituoso & 261 & 705 & 652 & 1144 & 1242 & 1305 & 1225 & 1198 & 549 & 259 \\
\hline retardado & 856 & 1313 & 1463 & 1458 & 1925 & 1491 & 1114 & 1135 & 505 & 143 \\
\hline inválido & 1120 & 3778 & 1568 & 2366 & 1950 & 1974 & 1705 & 1256 & 888 & 559 \\
\hline
\end{tabular}

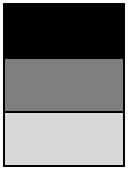

expressão com mais incidência

expressão em $2^{\circ}$ lugar de mais incidência

expressão em $3^{\circ}$ lugar de mais incidência

\footnotetext{
${ }^{7}$ Disponível de forma pública pelo endereço eletrônico <http://acervo.oglobo.globo.com/busca/?busca=> acesso em 16/07/2016. O site de buscas do Jornal O Globo não diferencia expressões plural e singular e fonetiza a busca. Permite a busca desde 1921 em todos os cadernos. Não foi identificado se necessariamente o verbete faz referência à pessoa.
} 
O Jornal O Globo acompanha a tendência já constatada na Folha de São Paulo de não priorizar o uso da nomenclatura atual "pessoas com deficiência". Eis que expressão mais incidente desde a década de 60 é "deficientes(s)", mas com sensível crescimento do uso da expressão adotada internacionalmente nas últimas décadas.

Do mesmo modo do Jornal anterior constata-se evolução dos termos com o passar das décadas, e assim palavras como "inválidos", "retardados", "defeituoso", "paralítico", dentre outras, cederam espaço para "portador de deficiência", "deficientes", "pessoas com deficiência".

\section{JUSTIFICATIVA CIENTÍFICA PARA UMA NOVA NOMENCLATURA}

Em que pese a forma como é vista a deficiência tenha evoluído ao longo dos tempos, a diversidade ainda pode ser sinônimo de adversidade. Pesquisadores como Piccolo \& Mendes (2013) entendem que a imposição de uma ordem natural é que coincide com os grupos dominantes, que procura classificar o que se distingue desta ordem pela ausência de algo. De tal modo, o cadeirante é um não caminhante, o surdo é alguém normal subtraído da faculdade de audição, o cego é um não vidente, o homoafetivo é um não heterossexual, a mulher um não homem, o negro um não branco. Piovesan (2006) registra que as mais graves violações aos direitos humanos tiveram como fundamento a dicotomia do "eu versus o outro", em que a diversidade era motivo para aniquilar direitos, ou seja, a "diferença" era justificativa para designar o 'outro' como um ser menor em dignidade e direitos, como ocorreu com "as violações da escravidão, do nazismo, do sexismo, do racismo, da homofobia, da xenofobia".

É válido, esta pesquisa acrescentar outra forma contemporânea de intolerância, o capacitismo ligado à discriminação ou preconceito contra a deficiência.

A expressão capacitismo até o momento (2020) "não consta como verbete encontrado" nos dicionários de língua portuguesa do Brasil (Aurélio e Michaelis, CAPACITISMO, 2020a, 2020b), nem de Portugal (Prebiram, CAPACITISMO, 2020c). Trata-se de uma livre tradução dos termos ableism (EUA e Austrália) ou disablism (Reino Unido), locais onde também é um termo relativamente novo, usado na academia por alguns ativistas para retratar a questão da discriminação ou preconceito decorrente de intolerância à deficiência. Nestes termos, ableism já consta no dicionário Oxford English (2020), ao passo que mais próximo de disablism é apresentada a expressão disablist. 


\section{UM ESTUDO SOBRE A EVOLUÇÃO DAS TERMINOLOGIAS DA EXPRESSÃO “PESSOAS COM \\ DEFICIÊNCIA": A PROPOSIÇÃO DE UMA NOVA NOMENCLATURA COMO CONCRETIZAÇÃO DA \\ DIGNIDADE HUMANA CONTEMPORÂNEA}

Mais do que um definidor, "a norma guarda consigo um elemento de segregação implícito, pois o diferente do preferível não é o indiferente, mas o refutável, o detestável, aquele que se deve evitar” (PICCOLO \& MENDES, 2013). A normatização não apaga a diferença, ao contrário, ela a demarca em um estágio inicial e depois a considera como de menor valia, dito de outro modo, a deficiência não é negada pela sociedade, mas reconhecida explicitamente para posteriormente ser carregada de símbolos esteriotipados a começar por sua própria nomenclatura. Neste diapasão aponta Rios (2002), ao debruçar seus estudos sobre a estigmatização da homoafetividade, que em uma democracia constitucional, sob pena dos padrões da pretensa científica normalidade serem aceitos acriticamente, devem ser debatidos, haja vista que, muitas vezes, os padrões representam o estabelecimento de relações de domínio social sobre determinadas grupos estigmatizados como "anormais/doentes/loucos" com a finalidade de os excluir, inclusive culpando-os, pela ausência do pleno reconhecimento social.

Como apresentado alhures, a nomenclatura utilizada para reconhecer o grupo de pessoas com deficiência tem sofrido várias mudanças, mas o progresso, principalmente na seara do trabalho, objeto de campo deste estudo, depende, simultaneamente, de políticas que valorizem a todos de modo igual e, da construção de uma concepção neutra da deficiência, a começar pela reanálise de sua nomenclatura atual que, ao adotar a expressão pessoa com deficiência, já carreia a ideia de "déficit" por produzir no discurso, uma aparência de "inferioridade" e de "incapacidade" automaticamente a todos independentemente de qual seja o grau de impedimento. Ora, ter uma diversidade, independentemente da funcionalidade - física, mental, intelectual ou sensorial - não implica necessariamente deficiência na realização de algo que pode ser feito com eficiência tanto quanto fosse realizado por "pessoa sem deficiência".

Nesta esteira é importante ressaltar que todos os seres humanos possuem modelos de representação do mundo e são estes modelos que orientam as ações. Contudo, por não serem estruturas estáticas é que estão em constante evolução. Deve-se então, na medida das modificações da cultura social, colocar tais modelos à prova e torná-los passíveis de questionamentos (HARLOS \& DENARI, 2012) visando ao progresso com a ruptura de eventual demonização.

A linguagem é capaz de produzir, modificar e direcionar o pensamento e as práticas sociais e, dialeticamente, também é modificada, produzida e orientada por mudanças de conceitos. 
Percebe-se, neste ínterim, o disposto por Harlos \& Denari (2012, p. 50), que "seja pelo desconhecimento de palavras mais adequadas; pelo temor de mexer em termos consolidados pelo uso popular ou acadêmico; ou simplesmente pela não percepção da incoerência entre os termos adotados e as concepções assumidas" em dadas circunstâncias, estabelece-se uma "desatualização" entre as palavras adotadas para se referir a algo ou alguém, o que desencadeia uma banalização dos nomes com a consequente acomodação terminológica.

Conclusões de recentes estudos realizados por PAGLIUCA et al. (2015), que ao realizarem a pergunta "como preferem ser chamadas" a 40 pessoas com deficiência visual, a 40 com deficiência auditiva e a 40 com deficiência motora, resultou naqueles que preferem ser denominados surdos $(97,5 \%)$; com deficiência visual $(45,0 \%)$ e ou cegos $(45,0 \%)$ aqueles com limitação motora que não aceitam a denominação de pessoa com deficiência motora $(72,5 \%)$ ou cadeirante $(95 \%)$. O estudo mostra as evidências de rejeição às palavras incapacidade, perda, restrição, déficit (deficiência), impedimento e exclusão, presentes nos enunciados relacionados na literatura e legislação. Apenas o atributo "limitação" é reconhecido e aceito positivamente por estes grupos na seguinte proporção: deficientes auditivos $(40,0 \%)$, visuais $(80,0 \%)$ e motora $(62,5 \%)$.

Outros estudos, com a guisa da necessidade de um termo que tente eliminar a negatividade simbólica de pejorativos que denotem incapacidade, deficiência, impedimento, e reforce a sua essência na diversidade, sugerem a expressão "pessoa com diversidade funcional" utilizado na Espanha pela primeira vez em maio de 2005, em uma comunidade virtual denominada "Fórum de Vida Independente" (http://es.groups.yahoo.com/group/vidaindependiente/ - criado em 2001, composto em sua maioria por pessoas com diversidade funcional e se baseia na filosofia do Movimento de Vida independente) (ROMAÑACH; LOBATO, 2005), em substituição ao que é comumente conhecido como "pessoa com deficiência" (PALACIOS; ROMAÑACH, 2006) e, por conseguinte, é mais uma tentativa de humanizar a expressão.

Como enfatizam Harlos \& Denari (2012, p. 53 ss.) ao fulcrarem seus estudos nos precursores teóricos espanhóis Agustina Palacios e Javier Romañach, a nomenclatura diversidade funcional parte da ideia de que as expressões anteriores sustentavam pressupostos negativos da deficiência ao adotar/manter o uso de expressões como "deficiência" e pela pouca ênfase na consideração da diversidade funcional como parte da diversidade social. Esta nova terminologia baseia-se na ideia de que nos modelos de interpretação dos Estudos da 


\section{UM ESTUDO SOBRE A EVOLUÇÃO DAS TERMINOLOGIAS DA EXPRESSÃO “PESSOAS COM \\ DEFICIÊNCIA": A PROPOSIÇÃO DE UMA NOVA NOMENCLATURA COMO CONCRETIZAÇÃO DA \\ DIGNIDADE HUMANA CONTEMPORÂNEA}

Deficiência, a diversidade funcional foi vista como expressão de um mal, seja de origem individual e biológica, seja de origem social e, embora reconheça que o modelo social tenha contribuído para desmedicalizar a diversidade funcional, na maior parte dos países persistiram uma série de estigmas em relação ao conjunto de pessoas em questão. Dentre estes estigmas, inclui-se o mito da incapacidade para o trabalho das pessoas com deficiência. O modelo da diversidade assume a dignidade humana como eixo teórico - elemento inerente a todos os seres humanos que alcançou o patamar de ser reconhecido como direito desvinculado de capacidade e eficiência.

Sobre o caráter e extensão dos direitos humanos da diversidade, Piovesan (2006, p.28) assinala que “(...) a implementação dos direitos humanos requer a universalidade e a individualidade desses direitos, acrescidas do valor da diversidade.” Diversidade é exatamente o termo que, proveniente dos estudos biológicos, mais tem sido utilizado na disseminação da ideia de que o ser humano não tem uma única identidade, um único corpo ou, menos ainda, uma única forma de pensar.

Neste sentido, a pessoa em si é uma das diversas possibilidades de ser e estar no mundo e não propriamente a incapacidade ou a deficiência como a esteira em que os conceitos foram construídos em abordagens que não a de direitos ou a relacional.

\section{CONSIDERAÇÕES FINAIS:}

Conclui pela necessidade de novos estudos que conduzam a busca de uma denominação que seja mais universalmente aceita.

Todavia, no momento, tendo em vista a deficiência baseada no modelo de direitos humanos (PALACIOS; ROMAÑACH, 2006), revela-se a necessidade de se acabarem com os paradoxos terminológicos presentes em expressões como eficiência e deficiência, e que sejam criados termos que denotem uma identidade "não negativa" do grupo em questão, sendo então sugeridos como principais expressões mulheres e homens com diversidade funcional e/ou pessoas com diversidade funcional. Trata-se de uma opção com o intuito de ressignificar paradigmas ao abandonar palavras que historicamente se consolidaram com tom pejorativo, 
buscando por dignidade plena, extrínseca (relativa aos direitos humanos) e intrínseca (relativa ao valor inerente a cada ser humano) $)^{8}$.

Há que se destacar que a adoção da expressão pessoa com diversidade funcional pode, como nas demais expressões, levar a uma banalização da condição de deficiência e estigmatizar novamente, com o transcorrer do tempo, o termo ou os discursos. Todavia, parece se tratar, atualmente, da expressão que emergencialmente mais humaniza a imagem da coletividade do grupo de modo não negativo, isto é, de modo que não reforce estigmas e posturas preconceituosas viabilizando, também por meio desta sensibilidade e cuidado, maiores chances de se garantir a evolução do desenvolvimento social. Se com o passar do tempo a nova nomenclatura tornar-se estigmatizada, compete aos pesquisadores sugerirem concepções dotadas de neutralidade à época.

\section{REFERÊNCIAS BIBLIOGRÁFICAS:}

ABLEISM, DISABLISM, D. Oxford English online. Disponível em: <https://en.oxforddictionaries.com/>. Acesso em: 15 fev. 2020.

\section{ALBRECHT, G. L.; SEELMAN, K. D.; BURY, M. Handbook of disability studies.} Thousand Oaks, CA: Sage, 2001.

ANSELMO, M. W. A representação discursiva de minorias sociais na mídia de massa: as pessoas com deficiência no jornal folha de s.paulo. Porto Alegre: Dissertação (Mestrado em Comunicação) - Universidade Estadual Paulista (Unesp) “Júlio De Mesquita Filho" Faculdade De Arquitetura, Artes e Comunicação, 2017.

BRASIL. Lei n. 3.071, de 1 de janeiro de 1916 que/ institui o Código Civil dos Estados Unidos do Brasil. Disponível em: <http://www.planalto.gov.br/ccivil_03/leis/L3071.htm>. Acesso em: 1 março. 2020.

Constituição da República Federativa do Brasil. 1988. Disponível em: <http://www.planalto.gov.br/ccivil_03/constituicao/constituiçao.htm>. Acesso em: 10 out. 2016.

Lei 8.213, 24 de julho de 1991. Dispõe sobre os planos de benefícios da previdência social e dá outras providências. Disponível em: 〈http:>. Acesso em: $20 \mathrm{dez}$. 2015 .

.Decreto Legislativo n. 186. Aprova o texto da Convenção sobre os Direitos das

\footnotetext{
${ }^{8}$ Com base nos estudos propostos por Agustina Palacios e Javier Romañach, os pesquisadores Harlos \& Denari (2012, p. 53 ss) explicam que a perspectiva extrínseca tem se demonstrado insuficiente para resolver assuntos relacionados com a dignidade intrínseca (interna, relativa ao valor inerente a cada ser humano) das pessoas com diversidade funcional e por isso, a Bioética é adotada como base epistemológica complementar para constituição do modelo da diversidade, para então se debater o valor intrínseco, inviolável e inalienável de cada vida humana (dignidade intrínseca).
} 


\section{UM ESTUDO SOBRE A EVOLUÇÃO DAS TERMINOLOGIAS DA EXPRESSÃO “PESSOAS COM \\ DEFICIÊNCIA": A PROPOSIÇÃO DE UMA NOVA NOMENCLATURA COMO CONCRETIZAÇÃO DA \\ DIGNIDADE HUMANA CONTEMPORÂNEA}

Pessoas com Deficiência e de seu Protocolo Facultativo, assinados em Nova Iorque, em 30 de março de 2007. Disponível em:

<http://www2.camara.leg.br/legin/fed/decleg/2008/decretolegislativo-186-9-julho-2008-

577811-publicacaooriginal-100742-pl.html>. Acesso em: 28 jun. 2016.

CAPACITISMO. Dicionário Aurélio online. Disponível em:

<https://dicionariodoaurelio.com/busca.php?q=capacitismo>. Acesso em: 15 FEV. 2020.

Dicionário Michaelis online. Disponível em:

$<$ http://michaelis.uol.com.br/busca? $\mathrm{r}=0 \& \mathrm{f}=0 \& \mathrm{t}=0 \&$ palavra=capacitismo $>$. Acesso em: 15 FEV. 2020.

Dicionário Prebiream online. Disponível em:

<https://www.priberam.pt/dlpo/CAPACITISMO>. Acesso em: 15 FEV. 2020c.

CARLI, R. De. Deficiente versus pessoa portadora de deficiência : uma análise discursiva dos jornais zero hora e correio do povo deficiente versus pessoa portadora de deficiência : uma análise discursiva dos jornais zero hora e correio do povo. 2003. Dissertação (Mestrado em Comunicação) - Universidade Federal do Rio Grande do Sul (UFRGS), Porto Alegre, 2003.

DEVOTTA, K.; WILTON, R.; YIANNAKOULIAS, N. Representations of disability in the Canadian news media : a decade of change? Disabil Rehabil, v. 35, n. 22, p. 1859-1868, 2013.

DIAS, R. R.; PETRUSKI, M. Penso, logo, eu existo! Entre representações e afirmações identitárias de pessoas com deficiência a partir de imagens da mídia. Publicatio UEPG, v. 25, n. 1, 2017. Disponível em: 〈http://177.101.17.124/index.php/sociais/about〉.

EMMA, B.; WATSON, N.; PHILO, G. Bad news for disabled people: how the newspapers are reporting disability. London: Strathclyde Centre for Disability Research and Glasgow Media Unit, 2011.

GARCIA, V. G. Pessoas com deficiência e o mercado de trabalho - histórico e contexto contemporâneo. Campinas: Tese (Doutorado em Desenvolvimento Econômico) Universidade Estadual de Campinas, 2010.

GOGGIN, G. Disability, Media, and the Politics of Vulnerability. Asia Pacific Media Educator, v. 19, p. 1-13, 2009. Disponível em:

$<$ http://ro.uow.edu.au/cgi/viewcontent.cgi?article=1295\&context=apme>.

GUGEL, M. A. A pessoa com deficiência e sua relação com a história da humanidade. Disponível em: <http://www.ampid.org.br/ampid/Artigos/PD_Historia.php>. Acesso em: 1 fev.2020.

HALLER, B.; DORRIES, B.; RAHN, J. Media labeling versus the US disability community identity: a study of shifting cultural language. Disability \& Society, v. 21, n. 1, p. 61-75, 2006.

HARLOS, F. E.; DENARI, F. E. Palavras, conceitos e preconceitos para incluir pessoas com diversidade funcional. Revista Géfyra, p. 49-55, 2012. Disponível em:

$<$ http://docplayer.com.br/22923808-Palavras-conceitos-e-preconceitos-para-incluir-pessoascom-diversidade-funcional.html>. 
HARNETT, A. Escaping the Evil Avenger and the Supercrip: Images of Disability in Popular Television. rish Communication Review, v. 8, n. 1, p. 21-29, 2000. Disponível em: $<$ http://arrow.dit.ie/icr/vol8/iss1/3>.

HUNT, P. Discrimination: disabled people and the media. Contact, v. 70, p. 45-48, 1991. Disponível em: <http://disability-studies.leeds.ac.uk/files/library/Barnes-Media.pdf>.

JONES, S. C. Representations of autism in Australian print media. Disability \& Society, v. 24, n. 1, p. 5-18, 2009. Disponível em:

$<$ http://www.tandfonline.com/doi/abs/10.1080/09687590802535345? src=recsys\&journalCode= cdso20>.

OLIVER, M. The politics of disablement: a sociologocal approach. New York: St. Martin's Press, 1990.

ONU. Organização das Nações Unidas. Convenção da ONU sobre os Direitos das Pessoas com Deficiência, 2006. Disponível em

<http://www.un.org/disabilities/default.asp?navid=14\&pid=150> Acesso em: 1 jun. 2016.

PAGLIUCA, L.; OLIVEIRA, P.; MARIANO, M. R.; SILVA, J. M.; ALMEIDA, P. C. De; OLIVEIRA, G. Pessoa com deficiência: construção do conceito por esta população. Revista Rene, v. 16, n. 5, p. 705-713, 2015.

PALACIOS, A.; ROMAÑACH, J. El modelo de la diversidad. La Bioética y los Derechos Humanos como herramientas para alcanzar la plena dignidad en la diversidad funcional. Diversitas, 2006.

PASTORE, J. Oportunidade de trabalho para portadores de deficiência. São Paulo: LTR, 2001.

PHILLIPS, S. D. Representations of disability in print news media in postsocialist Ukraine.

Disability \& Society, v. 27, n. 4, p. 487-502, 2012. Disponível em:

<http://www.tandfonline.com/doi/abs/10.1080/09687599.2012.662826>.

PICCOLO, G. M.; MENDES, E. G. Sobre formas e conteúdos: a deficiência como produção histórica. Revista Perspectiva, v. 31, n. 1, 2013.

PINTO, P. C. Dilemas da diversidade: interrogar a deficiência, o género e o papel das políticas públicas em portugal. Lisboa: Fundação Calouste Gulbenkian - Fundação para a Ciência e Tecnologia, 2012.

PIOVESAN, F. Direitos humanos e justiça internacional: um estudo comparativo dos sistemas regionais europeu, interamericano e africano. São Paulo: Saraiva, 2006.

RIOS, R. R. O princípio da igualdade e a discriminação por orientação sexual. São Paulo: Revista dos Tribunais, 2002.

ROMAÑACH, J.; LOBATO, M. Diversidad Funcional nuevo término para la lucha por la dignidad en la diversidad Humana. Disponível em:

<http://www.minusval2000.com/relaciones/vidaIndependiente/diversidad_funcional.html>. Acesso em: 15 nov. 2016.

SASSAKI, R. K. Inclusão: construindo uma sociedade para todos. Rio de Janeiro: WVA, 


\section{UM ESTUDO SOBRE A EVOLUÇÃO DAS TERMINOLOGIAS DA EXPRESSÃO “PESSOAS COM DEFICIÊNCIA": A PROPOSIÇÃO DE UMA NOVA NOMENCLATURA COMO CONCRETIZAÇÃO DA \\ DIGNIDADE HUMANA CONTEMPORÂNEA}

2002.

Vida independente: história, movimento, liderança, conceito, filosofia e fundamentos. 2003. RNR, São Paulo, 2003.

SHAKESPEARE, T. Art and lies? Representations of disability on film. In: CORKER, M.; FRENCH, S. (Ed.). Disability Discourse Buckingham. Philadelphia: Open University Press, 1999. p. 164-172.

SILVA, O. M. da. A epopéia ignorada - a pessoa deficiente na história do mundo de ontem e de hoje. São Paulo: CEDAS, 1987.

SILVEIRA, B. R. Entre a vitimização e a divinização: a pessoa com deficiência em viver a vida. Porto Alegre: Dissertação (Mestrado em Comunicação) - Pontifícia Universidade Católica do Rio Grande do Sul, 2012.

SILVERS, A. On the possibility and desirability of constructing a neutral conception of disability. Theoretical Medicine, v. 24, p. 471-487, 2003.

VIVARTA, V. (coord. . Mídia e Deficiência no BrasilBrasília, 2003. .

WENDELL, S. The rejected body: feminist pholosophical reflections on disability. New York: Routledge, 1996. 